\title{
Effects of combined application of nitrogen fertilizer and biochar on the nitrification and ammonia oxidizers in an intensive vegetable soil
}

Qing-Fang Bi ${ }^{1,3+}{ }^{+}$Qiu-Hui Chen ${ }^{4 \dagger}$, Xiao-Ru Yang ${ }^{3}$, Hu Li $^{3}$, Bang-Xiao Zheng ${ }^{3}$, Wei-Wei Zhou ${ }^{1}$, Xiao-Xia Liu ${ }^{5}$, Pei-Bin Dai ${ }^{6}$, Ke-Jie Li ${ }^{2}$ and Xian-Yong Lin ${ }^{1,2^{*}}$

\begin{abstract}
Soil amended with single biochar or nitrogen $(\mathrm{N})$ fertilizer has frequently been reported to alter soil nitrification process due to its impact on soil properties. However, little is known about the dynamic response of nitrification and ammonia-oxidizers to the combined application of biochar and $\mathrm{N}$ fertilizer in intensive vegetable soil. In this study, an incubation experiment was designed to evaluate the effects of biochar and $N$ fertilizer application on soil nitrification, abundance and community shifts of ammonia-oxidizing bacteria (AOB) and ammonia oxidizing archaea (AOA) in Hangzhou greenhouse vegetable soil. Results showed that single application of biochar had no significant effect on soil net nitrification rates and ammonia-oxidizers. Conversely, the application of only $N$ fertilizer and $N$ fertilizer + biochar significantly increased net nitrification rate and the abundance of $A O B$ rather than $A O A$, and only $A O B$ abundance was significantly correlated with soil net nitrification rate. Moreover, the combined application of $N$ fertilizer and biochar had greater effect on $\mathrm{AOB}$ communities than that of the only $\mathrm{N}$ fertilizers, and the relative abundance of 156 bp T-RF (Nitrosospira cluster 3c) decreased but 60 bp T-RF (Nitrosospira cluster 3a and cluster 0) increased to become a single predominant group. Phylogenetic analysis indicated that all the AOB sequences were grouped into Nitrosospira cluster, and most of AOA sequences were clustered within group $1.1 \mathrm{~b}$. We concluded that soil nitrification was stimulated by the combined application of $\mathrm{N}$ fertilizer and biochar via enhancing the abundance and shifting the community composition of $\mathrm{AOB}$ rather than $\mathrm{AOA}$ in intensive vegetable soil.
\end{abstract}

Keywords: Nitrification, Ammonia-oxidizing community, Biochar, Vegetable soil

\section{Introduction}

Biochar, a carbon-rich product, was derived from the pyrolysis carbonization organic matter under anoxic or hypoxic and relatively low temperature conditions $\left(\leq 700{ }^{\circ} \mathrm{C}\right)$ (Lehmann and Joseph 2015). Biochar with its potential agronomic benefits has been largely certified to exhibit strong improvement on soil quality

\footnotetext{
*Correspondence: xylin@zju.edu.cn

${ }^{\dagger}$ Qing-Fang Bi and Qiu-Hui Chen contributed equally to this work

${ }^{1}$ Key Laboratory of Subtropical Soil Science and Plant Nutrition

of Zhejiang Province, College of Environmental \& Resource Sciences,

Zhejiang University, Hangzhou 310058, China

Full list of author information is available at the end of the article
}

(Lehmann 2007; Lehmann et al. 2006, 2011). To be specific, studies have indicated that adding biochar into soil could enhance nutrient availability and sequester carbon, increase soil $\mathrm{pH}$ and cation-exchange capacity as a soil conditioner, and also alter soil microbial populations resulting in impacting on nutrient cycling (Lehmann et al. 2011). For these reasons, biochar has been increasingly evaluated as a soil amendment to improve soil fertility generating higher productivity. Moreover, biochar play an important role in soil nitrogen $(\mathrm{N})$ cycle via reducing inorganic- $\mathrm{N}$ leaching and $\mathrm{N}_{2} \mathrm{O}$ emission (Pan et al. 2017; Singh et al. 2010; Spokas and Reicosky 2009; $\mathrm{Xu}$ et al. 2014), increasing biological $\mathrm{N}$ fixation (Rondon 
et al. 2007) and enhancing $N$ availability for crops (Zheng et al. 2013). Therefore, biochar may impact the process of soil nitrification.

Nitrification is a central process in the nitrogen cycle, by which microorganisms oxidize ammonium $\left(\mathrm{NH}_{4}{ }^{+}\right)$ to generate nitrate $\left(\mathrm{NO}_{3}{ }^{-}\right)$, making soil nitrogen available for crop growth (Kowalchuk and Stephen 2001). The rate-limiting step of nitrification is the oxidation of $\mathrm{NH}_{4}^{+}$, which is driven by ammonia-oxidizing bacteria $(\mathrm{AOB})$ and ammonia oxidizing archaea (AOA). Even though both $A O B$ and AOA have been demonstrated as key drivers in ammonia oxidation in agricultural soil (Jin et al. 2010; Li and Gu 2013), their functional importance differs from various environmental conditions ( $\mathrm{He}$ et al. 2007; Leininger et al. 2006).

Moreover, many studies have shown that biochar addition significantly accelerated soil nitrification and improved the amount of soil ammonia-oxidizing microorganisms (Nelissen et al. 2012; Song et al. 2013). In forest soil, the abundance of $\mathrm{AOB}$ and nitrification rate have been found to increase with the charcoal addition (DeLuca et al. 2006; Ball et al. 2010). This is explained by the biochar adsorption of nitrification-inhibiting compounds such as terpenes and phenols (Ball et al. 2010). Contrarily, some researches have shown that biochar addition had significant inhibiting effect on nitrification, which was attributed to the agricultural system with high nitrification rate (DeLuca et al. 2006) or the presence of nitrification-inhibiting compound ( $\alpha$-pinene) in the biochar (Clough et al. 2010). Given that the critical role of $\mathrm{AOA}$ and $\mathrm{AOB}$ in soil nitrification process, the effect of biochar in agricultural situations might be indirectly or partially via its impact on the ammonia-oxidizing community itself.

Compared with cereal production, more intensive cropping rotations and frequent irrigation, and much larger input of nutrients are always performed in the greenhouse vegetable system in China (Shen et al. 2010). That could lead to a series of problems such as soil acidification, salinization, hardening, and nutrient imbalance, causing soil degradation and yield reduction. Moreover, annual $\mathrm{N}$ fertilizer inputs are 3-4 times greater in the greenhouse vegetable system than that in the non-vegetable system (Ju et al. 2006), whereas the nitrogen use efficiency was very low in the intensive vegetable soil ( $\mathrm{He}$ et al. 2006). Therefore, those problems are becoming a serious challenge to establish the sustainable intensive vegetable agricultural. As mentioned before, biochar with special physical and chemical properties can be used as a soil amendment, and has significant effects on alleviating soil acidification, improving soil structure, increasing soil available nutrients and vegetable yield (Chan et al. 2007). However, to our knowledge, little is known about biochar and $\mathrm{N}$ fertilizer interaction on nitrification and ammonia-oxidizing microbial community in the intensive vegetable soil. Therefore, we performed an incubation experiment to unravel the dynamic response of nitrification and ammonia oxidizers to the single application $\mathrm{N}$ fertilizer (urea and $\left(\mathrm{NH}_{4}\right)_{2} \mathrm{SO}_{4}$ ) or biochar and the combined application of $\mathrm{N}$ fertilizer and biochar across a greenhouse vegetable soil. To differentiate the role of AOA and AOB, quantitative real-time PCR (qPCR) and terminal restriction fragment length polymorphism (T-RFLP) combined with clone libraries were used to determine the abundance and structure of ammonia-oxidizing microbial communities.

\section{Materials and methods}

\section{Soil description and soil sampling}

Soil sample was collected from a vegetable greenhouse in the urban-rural transitional area $\left(30^{\circ} 17^{\prime} \mathrm{N}, 120^{\circ} 13^{\prime}\right.$ E) of Hangzhou City, China. Vegetables have been cultivated intensively for 30-40 years at this site (Chen et al. 2008). The soil was sandy loam (clay $6.2 \%$, silt $33.7 \%$, sand 60.1\%) (Chen et al. 2015) with $3.1 \mathrm{~g} \mathrm{~kg}^{-1}$ total $\mathrm{N}(\mathrm{TN})$, $27.6 \mathrm{~g} \mathrm{~kg}^{-1}$ organic matter $(\mathrm{OM})$ and $\mathrm{pH}$ value of 7.0 . The collected soil samples from the top layer $(0-15 \mathrm{~cm})$ without any debris were grounded to pass through a 2-mm sieve after air-dried. A part of soil samples was used to measure the chemical properties, and the remainder were preserved for laboratory incubation experiment.

\section{Characterization of biochar}

Biochar used in this experiment was produced from rice straw, which was carbonized under hypoxic condition at $600{ }^{\circ} \mathrm{C}$. The biochar had a $\mathrm{pH}$ of 10.2 , a total carbon $(\mathrm{C})$ content of $53.7 \%$, a TN content of $1.2 \%$, a total hydrogen $(\mathrm{H})$ content of $1.2 \%$, a $\mathrm{H}: \mathrm{C}$ ratio of 0.3 , a C:N ratio of $53.5 \%$, a $35.1 \%$ ash content.

\section{Experimental design}

To revive soil microbial activity, the air-dried soil was pre-incubated at $25{ }^{\circ} \mathrm{C}$ and $60 \%$ of water-holding capacity (WHC) for 2 weeks. The experiment was conducted in $100 \mathrm{~mL}$ plastic jars containing $50 \mathrm{~g}$ soil with six treatments including control, urea, $\left(\mathrm{NH}_{4}\right)_{2} \mathrm{SO}_{4}, 2 \%$ biochar, $2 \%$ biochar + urea, $2 \%$ biochar $+\left(\mathrm{NH}_{4}\right)_{2} \mathrm{SO}_{4}$, and each treatment was replicated for three times. The amount of $2 \%$ biochar added to soil was $2 \mathrm{mg} \mathrm{kg}^{-1}$ soil, which was calculated corresponding to a nitrogen addition of $200 \mathrm{mg} \mathrm{N}$ $\mathrm{kg}^{-1}$ soil. All these jars were then incubated inside incubator at $25{ }^{\circ} \mathrm{C}$ for 48 days. During the incubation period, soil moisture contents were kept constant at $65 \%$ WHC by adding deionized water based on the weighing method. The destructive sampling was performed during incubation period of $0,1,3,7,14,21,28,35,42$ and 48 days. 


\section{Soil property analysis}

Soil $\mathrm{pH}$ was measured at a soil solution ratio of $1: 5(\mathrm{w} / \mathrm{v})$ with a $\mathrm{pH}$ meter. Soil organic matter was determined by external-heat potassium dichromate oxidation-colorimetric method (Nelson and Sommers 1982). TN contents were measured by the Kjeldahl method. Grain size distribution of the soil samples was measured by a Mastersizer 2000 Laser Grainsize (Mastersizer 2000 Laser Grainsize, Malvern Instruments, Worcestershire, UK). Soil ammonium $\mathrm{N}\left(\mathrm{NH}_{4}{ }^{+}-\mathrm{N}\right)$ and nitrate $\mathrm{N}\left(\mathrm{NO}_{3}{ }^{-}-\mathrm{N}\right)$ were extracted by $2 \mathrm{~mol} \mathrm{~L}^{-1} \mathrm{KCl}$ solution (soil/KCl, 1:5) and measured by a flow injection analyzer (FLA sta 5000 Analyzer, Foss, Denmark). Soil $\mathrm{NH}_{4}{ }^{+}-\mathrm{N}$ and $\mathrm{NO}_{3}{ }^{-}-\mathrm{N}$ contents at day 0 were determined using the preincubation soil. And the net nitrification rate $(n)$ was calculated following the Persson and Wirén (1995) equation:

$n\left(\mathrm{mg} \mathrm{N} \mathrm{kg}^{-1}\right.$ soil day $\left.^{-1}\right)=\frac{\left(\mathrm{NO}_{3}^{-}-\mathrm{N}\right)_{t 2}-\left(\mathrm{NO}_{3}^{-}-\mathrm{N}\right)_{t 1}}{t}$

Where $t$ is the number of days between two sampling time ( $t 2$ and $t 1$, day), and $\left(\mathrm{NO}_{3}{ }^{-}-\mathrm{N}\right)_{t 1}$ and $\left(\mathrm{NO}_{3}{ }^{-}-\mathrm{N}\right)_{t 2}$ are the nitrate concentrations at time 1 and time 2, respectively.

\section{Soil DNA extraction and quantitative real-time PCR of amoA genes}

Soil DNA was extracted from $\sim 0.5 \mathrm{~g}$ frozen samples using a FastDNA SPIN Kit for soil (Bio101, Vista, CA) according to the manufacturer's protocol. The DNA was stored at $-20{ }^{\circ} \mathrm{C}$ for the molecular analyses described below.

The abundances of $\mathrm{AOA}$ and $\mathrm{AOB}$ were determined via qPCR on a Bio-Rad CFX 1000 real-time PCR machine. Two primer pairs were used for detecting the AOA and AOB (Additional file 1: Table S1). Each PCR reaction was performed in a $20-\mu \mathrm{L}$ mixture containing $1 \mu \mathrm{L}$ of tenfold diluted DNA, $0.5 \mu \mathrm{M}$ of each primer and $10 \mu \mathrm{L}$ of SYBR Premix EX Taq ${ }^{\mathrm{TM}}$, following with PCR protocol: initial denaturation at $95{ }^{\circ} \mathrm{C}$ for $3 \mathrm{~min}, 40$ cycles of $95{ }^{\circ} \mathrm{C}$ for $10 \mathrm{~s}, 55^{\circ} \mathrm{C}$ for $30 \mathrm{~s}$ and $72{ }^{\circ} \mathrm{C}$ for $40 \mathrm{~s}$. Serial dilutions of linearized plasmids containing cloned amo $A$ genes were conducted to make calibration curves. Only one peak at a melting temperature $(\mathrm{Tm})$ was detected. Only the standard curves with PCR efficiencies of $90-110 \%$ and correlation coefficients $>0.99$ were employed in this study.

\section{T-RFLP of amoA genes for ammonia oxidizers}

For analysis of the ammonia oxidizers community, T-RFLP analysis was performed on DNA extracted from soil samples of all treatments at day 3 . The same primers used in the qPCR with forward primer labeled with 6-FAM (6-carboxyfluorescein) were used in the T-RFLP analyses (Additional file 1: Table S1). The AOA and AOB samples were digested with restriction enzymes by Hpy$\mathrm{CH} 4 \mathrm{~V}$ (NEB) and MspI (NEB), respectively. Fragment size was carried out with an ABI PRISM $3030 \times$ L genetic analyzer (Applied Biosystems, Warrington, UK). T-RFs (terminal restriction fragments) with sizes longer than $50 \mathrm{bp}$ and percentages higher than $1 \%$ were kept for cluster analysis and the rest fragments were discarded.

\section{Cloning and sequencing}

To identify the main T-RFs, the $\mathrm{AOB}$ and AOA clone libraries from the control soil were constructed with the same primers used in the qPCR analysis. Following manufacturer's instructions, clones were generated by a TOPO $^{\circledR}$ TA Cloning kit (Invitrogen, Carlsbad, CA). And the T-RFLPs were transformed into numerical data using ABI $3730 \times$ L DNA analyzer (Applied Biosystems). Phylogenetic analyses were conducted with MEGA software (Tamura et al. 2013). The sequences were performed using the BLAST program in the GenBank database. Nucleotide sequences of $a m o A$ genes for the clone libraries in this study have deposited in GenBank under the accession numbers MF616026-MF616122.

\section{Statistical analysis}

Correlation, variance analyses (ANOVA) and the multiple stepwise linear regression were performed by IBM SPSS Statistics version 21.0. Principal component analysis (PCA) were performed using $R$ studio with VEGAN package. All figures were generated using OriginPro 8.5.

\section{Results}

Dynamics of $\mathrm{NH}_{4}{ }^{+}-\mathrm{N}$ and $\mathrm{NO}_{3}{ }^{-}-\mathrm{N}$ concentrations

No significant differences of $\mathrm{NH}_{4}{ }^{+}-\mathrm{N}$ and $\mathrm{NO}_{3}{ }^{-}-\mathrm{N}$ concentrations were found between only biochar amended and control treatments (Fig. 1). The urea and $\left(\mathrm{NH}_{4}\right)_{2} \mathrm{SO}_{4}$ treatments showed an immediate $\mathrm{NH}_{4}{ }^{+}$release with the highest $\mathrm{NH}_{4}{ }^{+}-\mathrm{N}$ concentrations $(192.9$ and $177.7 \mathrm{mg} \mathrm{kg}^{-1}$ in the urea and $\left(\mathrm{NH}_{4}\right)_{2} \mathrm{SO}_{4}$ treatments, respectively) at day 1 , and dramatically declined, but was no significant difference compared to the control after incubation of 14 days (Fig. 1a). Whereas the concentrations of $\mathrm{NO}_{3}{ }^{-}-\mathrm{N}$ increased rapidly and then kept stable (Fig. 1b). With the combination of biochar and nitrogen fertilizer addition, the rate of decrease in the $\mathrm{NH}_{4}{ }^{+}-\mathrm{N}$ concentration was higher than the single application of $\mathrm{N}$ fertilizer treatments before day 7 , and $\mathrm{NO}_{3}{ }^{-}-\mathrm{N}$ concentration also showed greater increase.

For the net nitrification rate, there was no significant difference between the treatment with single application of biochar and control. Whereas the net nitrification rate significantly increased in the nitrogen fertilizer treatments (Fig. 2) $(p<0.05)$, which were greater in the $\left(\mathrm{NH}_{4}\right)_{2} \mathrm{SO}_{4}$ treatments $\left(24.8 \pm 3.8\right.$ and $32.8 \pm 1.6 \mathrm{mg} \mathrm{kg}^{-1}$ day $^{-1}$ at 

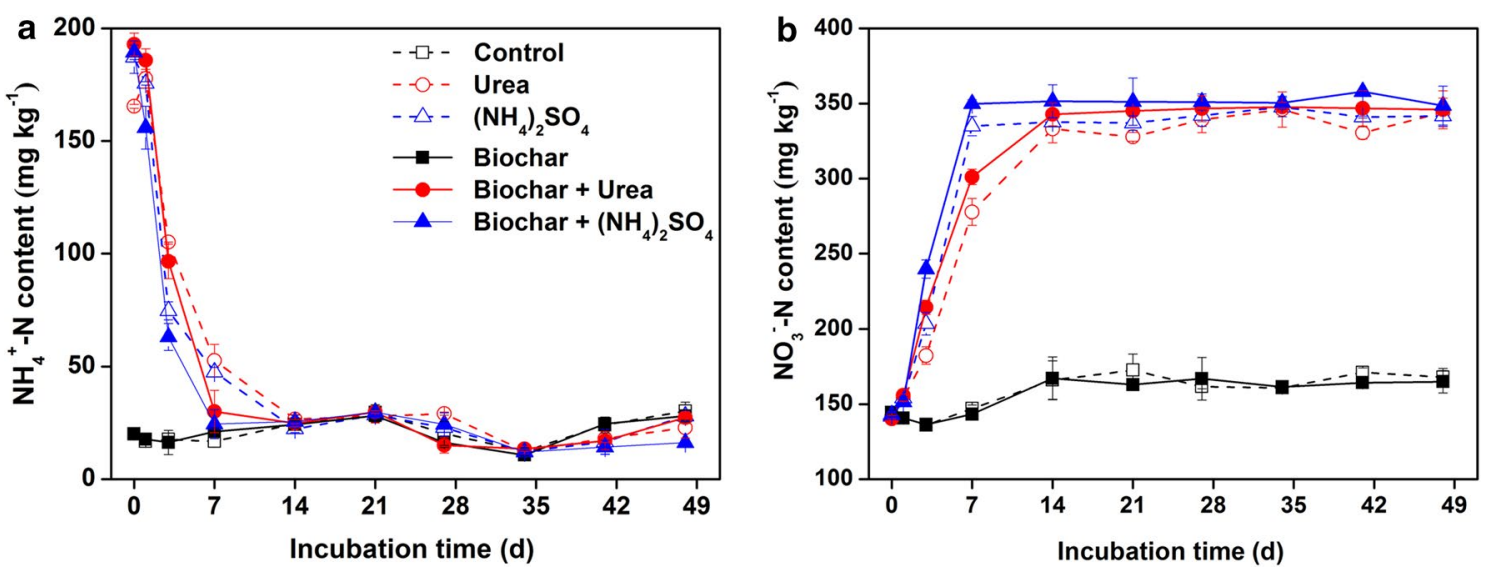

Fig. 1 Dynamics of $\mathrm{NH}_{4}{ }^{+}-\mathrm{N}(\mathbf{a})$ and $\mathrm{NO}_{3}{ }^{-}-\mathrm{N}(\mathbf{b})$ contents after the application of biochar and nitrogen fertilizer in the greenhouse vegetable soil

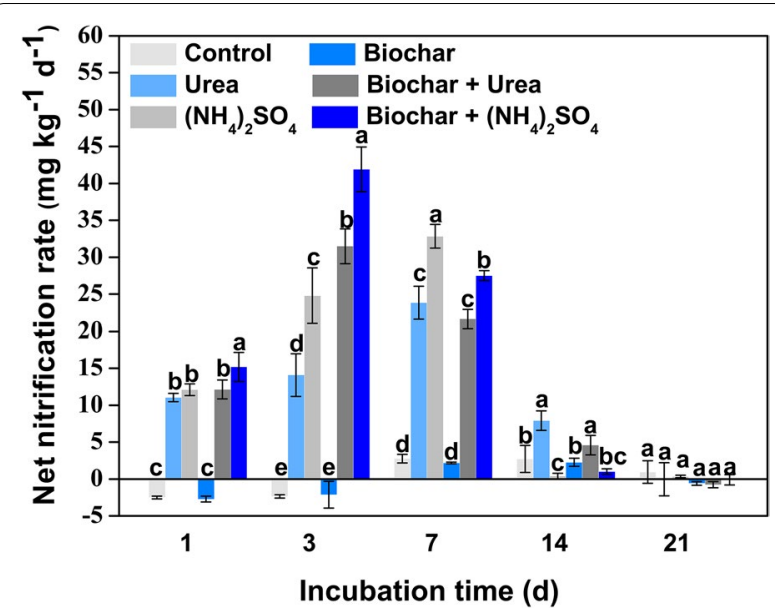

Fig. 2 Dynamics of net nitrification rate after the application of biochar and nitrogen fertilizer in the greenhouse vegetable soil

day 3 and day 7, respectively) than in the urea treatments $\left(14.1 \pm 2.9\right.$ and $23.8 \pm 2.2 \mathrm{mg} \mathrm{kg}^{-1}$ day $^{-1}$ at day 3 and day 7 , respectively). Additionally, for the biochar $+\mathrm{N}$ fertilizer treatments, the net nitrification rates were significantly higher than the single application of nitrogen fertilizers at day $3(p<0.05)$. Moreover, the net nitrification rate in the biochar $+\left(\mathrm{NH}_{4}\right)_{2} \mathrm{SO}_{4}$ treatment $(41.9 \pm 2.4 \mathrm{mg} \mathrm{kg}-1$ day $^{-1}$ ) was significantly higher in comparison with the biochar +urea treatment $\left(31.5 \pm 3.0 \mathrm{mg} \mathrm{kg}^{-1}\right.$ day $\left.^{-1}\right)$. These results indicated that the combined application of nitrogen fertilizer and biochar could enhance the nitrification of vegetable soil.

\section{Abundance of ammonia oxidizers}

During the incubation, the abundance of $a m o A$ in all treatments ranged from $2.3 \times 10^{8}$ to $5.1 \times 10^{8}$ copies $\mathrm{g}^{-1}$ dry soil and $1.0 \times 10^{8}$ to $3.0 \times 10^{8}$ copies $\mathrm{g}^{-1}$ dry soil for AOA and AOB, respectively (Fig. 3). In this vegetable soil, the abundance of AOA was higher than $\mathrm{AOB}$ and the ratios of AOA to AOB ranged from 1.0 to 3.8. During the incubation, there was no significant difference on the AOB abundance between the only biochar treatment and the control. More interestingly, the $\mathrm{AOB}$ amo $A$ gene abundances in all the $\mathrm{N}$ fertilizer amended treatments increased significantly $(p<0.05)$, which reached up from 1.6 to 2 times than the control at day 3. Furthermore, the $\mathrm{AOB}$ amoA gene abundances in the biochar $+\mathrm{N}$ fertilizer treatments were higher than that in the only $\mathrm{N}$ fertilizer treatments. Results also showed that the $\mathrm{AOB}$ amoA gene abundance was always higher in the $\left(\mathrm{NH}_{4}\right)_{2} \mathrm{SO}_{4}$ treatments than that in the urea treatments (Fig. 3a). However, the application of biochar and nitrogen fertilizer had no effects on AOA amoA gene abundance (Fig. 3b).

\section{Community compositions of $A O A$ and $A O B$}

As shown in the Fig. 4, the application of different fertilizers had a great impact on AOB community compositions, but only slight variations were observed in AOA. The predominant T-RFs in AOB community were 60 and $156 \mathrm{bp}$, which accounted for above $80 \%$ of the total community (Fig. 4a). Except for 264 bp T-RF, only biochar treatment showed no difference from the control on the AOB T-RFLP profiles. With the addition of $\mathrm{N}$ fertilizer, the relative abundance of $60 \mathrm{bp}$ T-RF increased significantly, but 156 bp T-RF decreased $(p<0.05)$. Moreover, the relative abundances of $60 \mathrm{bp} T-\mathrm{RF}$ were higher in the biochar $+\mathrm{N}$ fertilizer treatments than those in the only $\mathrm{N}$ fertilizer treatments. Additionally, the $235 \mathrm{bp}$ T-RF was not detected in the biochar $+\mathrm{N}$ fertilizer treatments. PCA analysis of the AOB T-RFLP profiles further revealed that the two axes explained $84.7 \%$, and the $\mathrm{AOB}$ community 

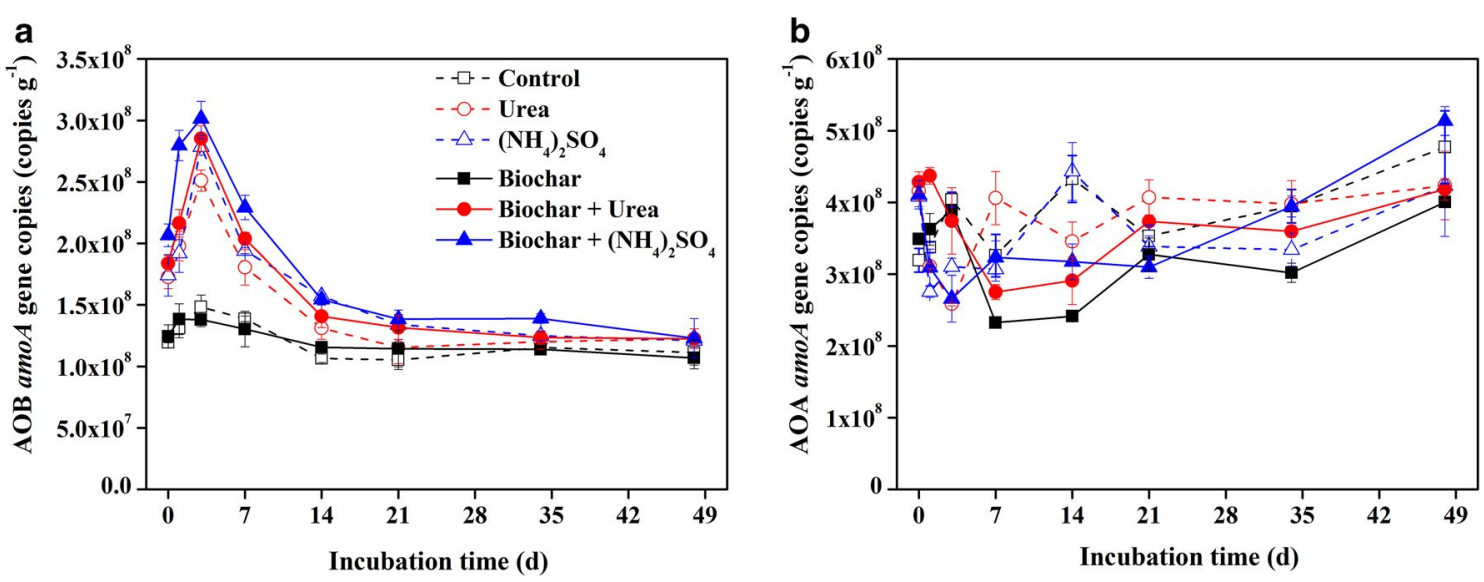

Fig. 3 Dynamics of AOA (a) and AOB (b) amoA gene copies after the application of biochar and nitrogen fertilizer in the greenhouse vegetable soil
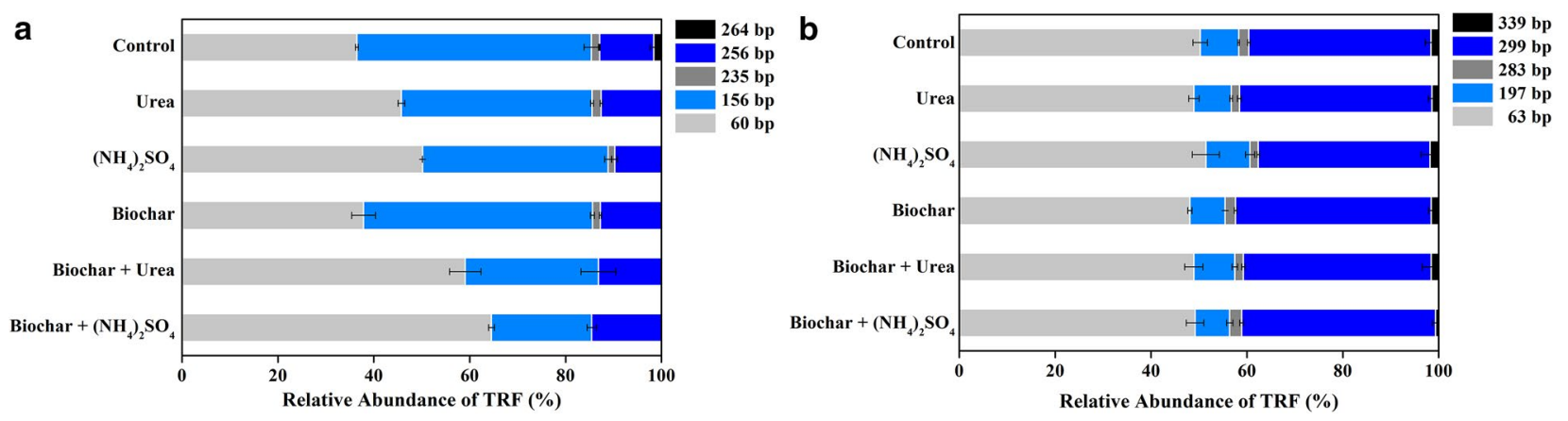

Fig. 4 Relative abundance (a) and principle component analysis (b) of the ammonia oxidizing bacterial T-RFs

composition was significantly influenced by biochar and $\mathrm{N}$ fertilizer (Additional file 1: Figure S1). Results showed that both the biochar and $\mathrm{N}$ fertilizer treatments were clearly separated from the control, whereas only biochar and only $\mathrm{N}$ fertilizer treatments and the biochar $+\mathrm{N}$ fertilizer treatments were clustered together. Moreover, the Shannon and Simpson index are normally used to characterize species diversity in a community. For AOB community, both the Shannon and Simpson index decreased significantly in the only $\left(\mathrm{NH}_{4}\right)_{2} \mathrm{SO}_{4}$ and biochar $+\mathrm{N}$ fertilizer treatments when compared with the control which were significantly reduced with the biochar and $\mathrm{N}$ fertilizer addition $(p<0.05)$ (Table 1). Overall, our results demonstrated that the $\mathrm{AOB}$ community diversity in treatments with combined application of biochar and $\mathrm{N}$ fertilizer shifted significantly.

\section{Phylogeny of $A O A$ and $A O B$}

The AOB phylogenetic tree showed that $A O B$ sequences were divided into five distinct clusters including Nitrosospira cluster 3a, 3b, 3c, cluster 0 and Nitrosospira sp.
Table 1 The Shannon index (H) and Simpson index (D) of $A O B$ and $A O A$ community structure diversity

\begin{tabular}{|c|c|c|c|c|}
\hline & \multicolumn{2}{|l|}{ AOB } & \multicolumn{2}{|l|}{$A O A$} \\
\hline & $\mathrm{H}$ & D & $\mathrm{H}$ & D \\
\hline Control & $1.099 a$ & $0.614 a$ & $1.063 a$ & $0.596 a$ \\
\hline Urea & $1.060 \mathrm{ab}$ & $0.616 a$ & $1.043 a b$ & $0.593 a$ \\
\hline$\left(\mathrm{NH}_{4}\right)_{2} \mathrm{SO}_{4}$ & $0.999 c$ & $0.589 b$ & $1.070 \mathrm{a}$ & $0.597 a$ \\
\hline Biochar & $1.049 b$ & $0.611 a$ & $1.058 \mathrm{a}$ & $0.596 a$ \\
\hline Biochar +Urea & $0.932 d$ & $0.555 c$ & $1.067 a$ & $0.599 a$ \\
\hline Biochar $+\left(\mathrm{NH}_{4}\right)_{2} \mathrm{SO}_{4}$ & $0.890 \mathrm{~d}$ & $0.518 d$ & $1.005 b$ & $0.583 a$ \\
\hline
\end{tabular}

Different letters indicate significance at $p<0.05$

Nsp65, affiliating to genus of Nitrosospira (Fig. 5). The 156 bp T-RF mainly belonged to Nitrosospira cluster 3c, the other 21\% belonged to Nitrosospira sp. Nsp65 and cluster 0 . And T-RF 60 bp distributed in various genera of Nitrosospira. The T-RFs of 235 and 256 bp were affiliated with Nitrosospira sp. Nsp65 and cluster 3a, respectively. 
The AOA phylogenetic analysis indicated that AOA sequences of vegetable soil (98\%) were highly homologous to Nitrososphaera gargensis, which belonged to group $1.1 \mathrm{~b}$, and only one sequence belonging to group 1.1a. The T-RFs of $197 \mathrm{bp}, 299 \mathrm{bp}$ and $63 \mathrm{bp}$ were closely aligned with group $1.1 \mathrm{~b}$, and the $283 \mathrm{bp}$ T-RF was affiliated with group 1.1a and group 1.1b.

\section{Discussion}

In this study, no significant differences of $\mathrm{NH}_{4}^{+}-\mathrm{N}$, $\mathrm{NO}_{3}{ }^{-}-\mathrm{N}$ concentrations and net nitrification rates were observed between only biochar addition and control treatment (Fig. 1), indicating that biochar addition had little effect on the soil nitrification in the absence of $\mathrm{N}$ fertilizer. This result may be caused by the limited $\mathrm{NH}_{4}{ }^{+}$ in the collected soil sample, which are the substrate of hydrolysis by ammonia-oxidizing microorganisms, or the biochar with the carbon-rich but nutrient-poor characteristic (Alburquerque et al. 2013). As expected, soil $\mathrm{NH}_{4}{ }^{+}-\mathrm{N}$ concentrations significantly increased after the addition of $\mathrm{N}$ fertilizer, and sharply decreased to an equilibrium at day 7 or day 14 (Fig. 1a). In contrast, the $\mathrm{NO}_{3}{ }^{-}-\mathrm{N}$ concentrations showed a rapid increase and also reached up an equilibrium correspondingly (Fig. 1b). These results suggested that when adding the $\mathrm{N}$ fertilizer, the conversion from ammonium to nitrate for crop growth via nitrification was immediate and rapid. Additionally, the net nitrification rate reached up to $42 \pm 3 \mathrm{mg} \mathrm{kg}^{-1} \mathrm{day}^{-1}$ in this study (Fig. 2), indicating that the $\mathrm{N}$ fertilizer provided an obvious promotion in the nitrification of vegetable soil via ammonia-oxidizing microorganisms. Moreover, the $\mathrm{NO}_{3}{ }^{-}-\mathrm{N}$ concentrations and net nitrification rates in the biochar $+\mathrm{N}$ fertilizer treatments were observed to be higher than only $\mathrm{N}$ fertilizer treatments, which reached a significant higher level at day 3 and day $7(p<0.05)$, respectively, demonstrating that the combined application of $\mathrm{N}$ fertilizer and biochar had a synergistic effect on soil nitrification. Our findings were consistent with the previous study, which indicated that crop growth were simulated applied with biochar and mineral fertilizer (Asai et al. 2009; Schulz and Glaser 2012; Van Zwieten et al. 2010). As for biochar, the ability of promoting nitrification could be attributed to the adsorption of inhibiting substances of nitrification such as phenols and terpene in biochar (Ball et al. 2010; Berglund et al. 2004; DeLuca et al. 2006). Furthermore, biochar could significantly increase soil organic carbon, resulting in high ratios of carbon to nitrogen, which could enhance soil nitrification to improve the bioavailability of nitrogen (Clough et al. 2013). In addition, Zhao et al. (2013) found that the soil pH increased significantly after combined application of biochar and $\mathrm{N}$ fertilizer in an acid agricultural soil, which was also promoted with the increase of the amount of biochar.
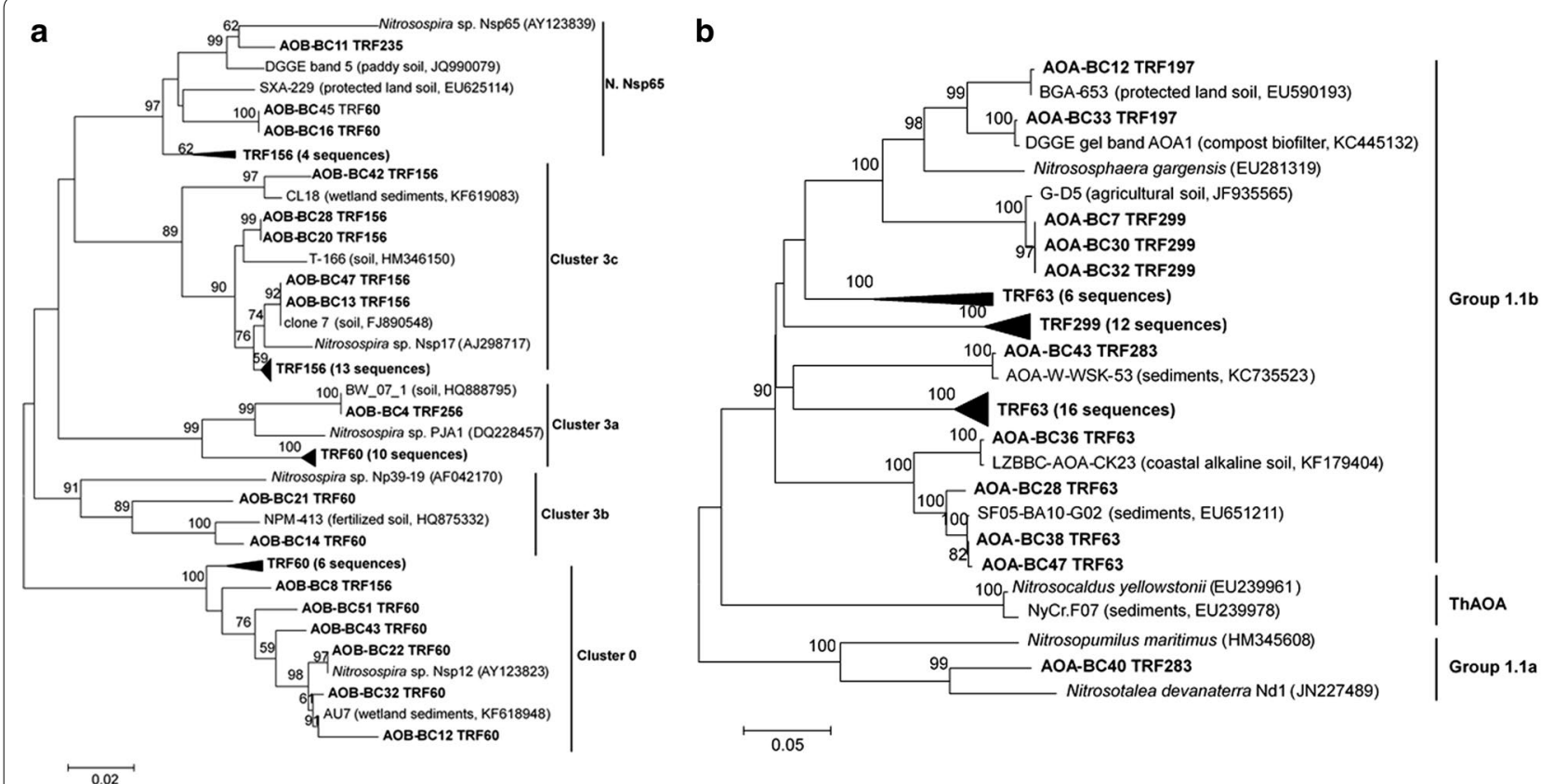

Fig. 5 Neighbor-joining phylogenetic tree of $\mathbf{a}$ bacterial amoA sequences and $\mathbf{b}$ archaeal amoA sequences retrieved from the vegetable soil. Sequences from this study are shown in bold and described as clone name (accession number) T-RF size. Reference sequences are described as clone name (environment, accession number). Bootstrap values (> 50\%) are indicated at branch points. The scale bar represents 5\% estimated sequence divergence. The accession numbers in GenBank were MF616026-MF616122 
The abundance of $\mathrm{AOB}$ increased significantly in $\mathrm{N}$ fertilizer treatments $(p<0.05)$, which was line with the higher net nitrification rate in these soils (Figs. 2 and 3a). Additionally, significantly positive correlation was also observed between net nitrification rate and $\mathrm{AOB}$ abundance rather than AOA abundance $\left(r=0.829^{* * *}, p<0.01\right)$ (Additional file 1: Table S2), permutational multivariate analyses also showed positive correlation in $\mathrm{AOB}$ abundance and the effects of different treatments and incubation time (Additional file 1: Table S3). This suggested that the increased abundance of $\mathrm{AOB}$ played a more direct positive role than AOA in the soil nitrification with $\mathrm{N}$ fertilizer, which was consistent with previous reports in natural and alkaline soil (Jia and Conrad 2009; Shen et al. 2008). Moreover, higher abundance of AOB was observed in $\mathrm{N}$ fertilizer + biochar treatments compared with only $\mathrm{N}$ fertilizer treatments, (Fig. 3a), indicating that combined application of $\mathrm{N}$ fertilizer with biochar could enhance the nitrification by increasing the abundance of AOB in this vegetable soil. However, the effects of biochar on ammonia-oxidizers were quite distinct from diverse soils. For example, with biochar addition in coastal saline soil, higher AOA abundance increased soil ammoxidation rate (Song et al. 2013). Whereas Prommer et al. (2014) found that biochar boosted both AOA and $\mathrm{AOB}$ abundances in agricultural soil, leading to the enhancement of soil potential nitrification rates. Overall, the increase in the amount of ammonia-oxidizing microorganisms associated with biochar addition may be due to the following four reasons. Firstly, large surface area and highly porous structure with water holding capacity and nutrient retention of biochar could provide resources for the specific metabolic needs of microorganisms (Steinbeiss et al. 2009). Secondly, biochar could improve living condition of biota by the increase of $\mathrm{pH}$ in acid soil (Ball et al. 2010). Thirdly, the source of carbon and nitrogen in biochar improve soil fertility. Finally, biochar might absorb the inhibiting substances such as polyphenols or tannins on nitrification (Ball et al. 2010; DeLuca et al. 2006). Nevertheless, some studies had reported that biochar addition showed no difference even a negative effect on soil nitrification (Clough et al. 2010; Spokas and Reicosky 2009). That may be due to the release of nitrification inhibitor such as ethylene and $\alpha$-pinene via biochar to reduce soil ammonia-oxidizing microorganism activity (Berglund et al. 2004; DeLuca et al. 2006), which was different on the parent materials and conditions during the formation of biochar.

The T-RFLP analysis showed that the AOB community structures varied from different treatments (Fig. 5). The dominance of Nitrosospira cluster 3 (contributing to $62 \%$ of the sequences) in AOB indicated that Nitrosospira cluster 3 played an important role in nitrification (Shen et al. 2011), whereas Nitrosomonas was not detected in the greenhouse vegetable soil (Fig. 5b). This was consistent with a previous study that Nitrosospira cluster 3 also dominated in a long-term fertilization sandy loam soil (Chu et al. 2007). Our results also revealed that the community structure and diversity of $\mathrm{AOB}$ in vegetable soil were significantly altered by the combined application of biochar and $\mathrm{N}$ fertilizer rather than the single application of biochar (Fig. 4). Compared with the control, the relative abundance of $60 \mathrm{bp}$ T-RF increased from 36.5 to $64.6 \%$ in the biochar $+\left(\mathrm{NH}_{4}\right)_{2} \mathrm{SO}_{4}$ treatment, which belonged to Nitrosospira cluster $3 \mathrm{a}$ and cluster 0 , suggesting that the combined application of biochar and $\mathrm{N}$ fertilizer stimulated microbial growth of the related cluster. However, 156 bp T-RF belonging to Nitrosospira cluster 3c showed a significant decrease. Dempster et al. (2011) also found AOB community shifts occurred in biochar $+\mathrm{N}$ fertilizer treatments but not in the single biochar added treatment. Moreover, the significant decrease of Shannon and Simpson index also reflected the reduction in community diversity of $\mathrm{AOB}$ with the combined addition of biochar and $\mathrm{N}$ fertilizer in this vegetable soil (Table 1). The dominant AOA was affiliated to group 1.1b containing 98\% sequences. Although many studies have indicated that AOA are considered to be the primary driver of nitrification (Chen et al. 2008; He et al. 2007; Leininger et al. 2006), in our study, there was no discernable changes in the AOA community after the combined application of $\mathrm{N}$ fertilizer and biochar, indicating the $\mathrm{AOB}$ community was more sensitive to the fertilization practice in vegetable soil. In agreement with our findings, extensive research have observed an obvious promotion effect of fertilizer on $\mathrm{AOB}$ community rather than AOA (Ai et al. 2013; Fan et al. 2011; Xia et al. 2011). In general, the variance in ecological niches of $\mathrm{AOB}$ and $\mathrm{AOB}$ are caused by their dissimilar sensitivity to soil properties (Shen et al. 2008). As AOB are considered to mainly dominated in the neutral and "nutrientrich" environment, whereas AOA are better to adapted to low $\mathrm{pH}$ and "nutrient-poor" environment (Schauss et al. 2009). Furthermore, the reason that the significant shift in $\mathrm{AOB}$ community occurred in this study, may be the increase of soil $\mathrm{pH}$ and nutrient contents after the biochar $(\mathrm{pH}=10.2)$ and $\mathrm{N}$ fertilizer addition.

In conclusion, our results revealed that $\mathrm{N}$ fertilizer with the addition of biochar significantly stimulated soil nitrification and shifted the AOB abundance and community. T-RFLP of AOB indicated that the combined application of $\mathrm{N}$ fertilizer and biochar significantly increased the 60 bp T-RF (Nitrosospira cluster 3a and cluster 0 ) but decreased 156 bp T-RF (Nitrosospira cluster 3c). On the contrary, there were no visible changes in the AOA community compared to AOB. Moreover, the positive 
correlation between net nitrification rate and $\mathrm{AOB}$ abundance, indicating that $\mathrm{AOB}$ rather than $\mathrm{AOA}$ was the dominant ammonia oxidizer to drive soil nitrification in intensive vegetable soil. This has important implications that the combined utilization of $\mathrm{N}$ fertilizer and biochar enable to promote the nitrogen use efficiency.

\section{Additional file}

Additional file 1: Table S1. Primers of AOA and AOB used for molecular analyses. Table S2. Pearson correlation between the abundance of $A O A / A O B$ and net nitrification rate. Table S3. Permutational multivariate analyses for the effects of different treatment (Treat) and incubation time (Time) on the abundance of AOA and AOB. Figure S1. The principal coordinates analysis (PCA) of AOB T-RFs in vegetable soils treated with urea, $\left(\mathrm{NH}_{4}\right)_{2} \mathrm{SO}_{4}$, biochar, biochar + urea, biochar $+\left(\mathrm{NH}_{4}\right)_{2} \mathrm{SO}_{4}$ based on Bray-Curtis distance.

\section{Abbreviations}

$\mathrm{N}$ : nitrogen; AOA: ammonia-oxidizing archaea; $\mathrm{AOB}$ : ammonia-oxidizing bacteria; QPCR: quantitative real-time PCR; T-RFLP: terminal restriction fragment length polymorphism; $\mathrm{NH}_{4}^{+}$: ammonium; $\mathrm{NO}_{3}^{-}$nitrate; $\mathrm{TN}$ : total nitrogen; OM: organic matter; C: carbon; H: hydrogen; WHC: water-holding capacity; T-RFs: terminal restriction fragments; ANOVA: variance analyses; PCA: principal component analysis.

\section{Authors' contributions}

XYL and QHC designed the experiments. QFB, QHC, PBD, KJL and WWZ performed the experiments. QFB and QHC analyzed the data. QFB wrote the manuscript. XRY, HL, BXZ and XYL revised the paper. All authors read and approved the final manuscript.

\begin{abstract}
Author details
${ }^{1}$ Key Laboratory of Subtropical Soil Science and Plant Nutrition of Zhejiang Province, College of Environmental \& Resource Sciences, Zhejiang University, Hangzhou 310058, China. ${ }^{2}$ MOE Key Laboratory of Environment Remediation and Ecological Health, College of Environmental \& Resource Sciences, Zhejiang University, Hangzhou 310058, China. ${ }^{3}$ Key Lab of Urban Environment and Health, Institute of Urban Environment, Chinese Academy of Sciences, Xiamen 361021, China. ${ }^{4}$ Nanjing Institute of Environmental Sciences, Ministry of Environmental Protection, Nanjing 210042, China. ${ }^{5}$ Zhejiang Agricultural Technology Extension Center, Hangzhou 310020, China. ${ }^{6}$ Department of Applied Engineering, Zhejiang Economic and Trade Polytechnic, Hangzhou 310018, China.
\end{abstract}

\section{Acknowledgements}

None.

\section{Competing interests}

The authors declare that they have no completing interests.

\section{Availability of data and materials}

The datasets supporting the conclusions of this article are included within the article and its Additional file 1.

\section{Consent for publication}

This article does not contain any individual person's data.

\section{Ethical approval and consent to participate}

This article does not contain any studies with human participants or animals performed by any of the authors.

\section{Funding}

This research was supported by the National Natural Science Foundation of China (41571130061), Strategic Priority Research Program of the Chinese
Academy of Sciences (B) (XDB15020402), and the Program for S\&T Cooperation Project of Zhejiang Province (CTZB-F150922AWZ-SNY1 (2)).

\section{Publisher's Note}

Springer Nature remains neutral with regard to jurisdictional claims in published maps and institutional affiliations.

Received: 10 August 2017 Accepted: 26 October 2017

Published online: 07 November 2017

\section{References}

Ai C, Liang G, Sun J, Wang X, He P, Zhou W (2013) Different roles of rhizosphere effect and long-term fertilization in the activity and community structure of ammonia oxidizers in a calcareous fluvo-aquic soil. Soil Biol Biochem 57:30-42. https://doi.org/10.1016/j.soilbio.2012.08.003

Alburquerque JA, Salazar P, Barrón V, Torrent J, del Campillo MdC, Gallardo A, Villar R (2013) Enhanced wheat yield by biochar addition under different mineral fertilization levels. Agron Sustain Dev 33(3):475-484. https://doi. org/10.1007/s13593-012-0128-3

Asai H, Samson BK, Stephan HM, Songyikhangsuthor K, Homma K, Kiyono Y, Inoue Y, Shiraiwa T, Horie T (2009) Biochar amendment techniques for upland rice production in Northern Laos. Field Crops Res 111(1-2):81-84. https://doi.org/10.1016/j.fcr.2008.10.008

Ball PN, MacKenzie MD, DeLuca TH, Montana WEH (2010) Wildfire and charcoal enhance nitrification and ammonium-oxidizing bacterial abundance in dry montane forest soils. J Environ Qual 39(4):1243. https://doi. org/10.2134/jeq2009.0082

Berglund LM, DeLuca TH, Zackrisson O (2004) Activated carbon amendments to soil alters nitrification rates in Scots pine forests. Soil Biol Biochem 36(12):2067-2073. https://doi.org/10.1016/j.soilbio.2004.06.005

Chan KY, Van Zwieten L, Meszaros I, Downie A, Joseph S (2007) Agronomic values of greenwaste biochar as a soil amendment. Aust J Soil Res 45(8):629. https://doi.org/10.1071/sr07109

Chen T, Liu X, Zhu M, Zhao K, Wu J, Xu J, Huang P (2008) Identification of trace element sources and associated risk assessment in vegetable soils of the urban-rural transitional area of Hangzhou, China. Environmental Pollution 151(1):67-78. https://doi.org/10.1016/j.envpol.2007.03.004

Chen Q, Qi L, Bi Q, Dai P, Sun D, Sun C, Liu W, Lu L, Ni W, Lin X (2015) Comparative effects of 3,4-dimethylpyrazole phosphate (DMPP) and dicyandiamide (DCD) on ammonia-oxidizing bacteria and archaea in a vegetable soil. Appl Microbiol Biotechnol 99(1):477-487. https://doi.org/10.1007/ s00253-014-6026-7

Chu H, Fujii T, Morimoto S, Lin X, Yagi K, Hu J, Zhang J (2007) Community structure of ammonia-oxidizing bacteria under long-term application of mineral fertilizer and organic manure in a sandy loam soil. Appl Environ Microbiol 73(2):485-491. https://doi.org/10.1128/AEM.01536-06

Clough TJ, Bertram JE, Ray JL, Condron LM, O'Callaghan M, Sherlock RR, Wells NS (2010) Unweathered wood biochar impact on nitrous oxide emissions from a bovine-urine-amended pasture soil. Soil Sci Soc Am J 74(3):852. https://doi.org/10.2136/sssaj2009.0185

Clough T, Condron L, Kammann C, Müller C (2013) A review of biochar and soil nitrogen dynamics. Agronomy 3(2):275-293. https://doi.org/10.3390/ agronomy 3020275

DeLuca TH, MacKenzie MD, Gundale MJ, Holben WE (2006) Wildfire-produced charcoal directly influences nitrogen cycling in ponderosa pine forests. Soil Sci Soc Am J 70(2):448. https://doi.org/10.2136/sssaj2005.0096

Dempster DN, Gleeson DB, Solaiman ZM, Jones DL, Murphy DV (2011) Decreased soil microbial biomass and nitrogen mineralisation with Eucalyptus biochar addition to a coarse textured soil. Plant Soil 354(1-2):311324. https://doi.org/10.1007/s11104-011-1067-5

Fan F, Yang Q, Li Z, Wei D, Cui X, Liang Y (2011) Impacts of organic and inorganic fertilizers on nitrification in a cold climate soil are linked to the bacterial ammonia oxidizer community. Microb Ecol 62(4):982-990. https://doi.org/10.1007/s00248-011-9897-5

He F, Chen Q, Jiang R, Chen X, Zhang F (2006) Yield and nitrogen balance of greenhouse tomato (Lycopersicum esculentum Mill.) with conventional 
and site-specific nitrogen management in Northern China. Nutr Cycl Agroecosyst 77(1):1-14. https://doi.org/10.1007/s10705-006-6275-7

He JZ, Shen JP, Zhang LM, Zhu YG, Zheng Ym YM, Di Xu MG (2007) Quantitative analyses of the abundance and composition of ammonia-oxidizing bacteria and ammonia-oxidizing archaea of a Chinese upland red soil under long-term fertilization practices. Environ Microbiol 9(12):3152. https://doi.org/10.1111/j.1462-2920.2007.01481.x

Jia Z, Conrad R (2009) Bacteria rather than Archaea dominate microbial ammonia oxidation in an agricultural soil. Environ Microbiol 11(7):1658-1671. https://doi.org/10.1111/j.1462-2920.2009.01891.x

Jin T, Zhang T, Yan Q (2010) Characterization and quantification of ammoniaoxidizing archaea (AOA) and bacteria (AOB) in a nitrogen-removing reactor using T-RFLP and qPCR. Appl Microbiol Biotechnol 87(3):1167-1176. https://doi.org/10.1007/s00253-010-2595-2

Ju XT, Kou CL, Zhang FS, Christie P (2006) Nitrogen balance and groundwater nitrate contamination: comparison among three intensive cropping systems on the North China Plain. Environ Pollut 143(1):117-125. https:// doi.org/10.1016/j.envpol.2005.11.005

Kowalchuk GA, Stephen JR (2001) Ammonia-oxidizing bacteria: a model for molecular microbial ecology. Annu Rev Microbiol 55(1):485-529

Lehmann J (2007) Bio-energy in the black. Front Ecol Environ 5(7):381-387

Lehmann J, Joseph S (2015) Biochar for environmental management: science, technology and implementation. Routledge, Abingdon

Lehmann J, Gaunt J, Rondon M (2006) Bio-char sequestration in terrestrial ecosystems - a review. Mitig Adapt Strat Glob Change 11(2):395-419. https://doi.org/10.1007/s11027-005-9006-5

Lehmann J, Rillig MC, Thies J, Masiello CA, Hockaday WC, Crowley D (2011) Biochar effects on soil biota—a review. Soil Biol Biochem 43(9):1812-1836. https://doi.org/10.1016/j.soilbio.2011.04.022

Leininger S, Urich T, Schloter M, Schwark L, Qi J, Nicol GW, Prosser Jl, Schuster SC, Schleper C (2006) Archaea predominate among ammonia-oxidizing prokaryotes in soils. Nature 442(7104):806-809. https://doi.org/10.1038/ nature04983

Li M, Gu JD (2013) Community structure and transcript responses of anammox bacteria, $A O A$, and $A O B$ in mangrove sediment microcosms amended with ammonium and nitrite. Appl Microbiol Biotechnol 97(22):98599874. https://doi.org/10.1007/s00253-012-4683-y

Nelissen V, Rütting T, Huygens D, Staelens J, Ruysschaert G, Boeckx P (2012) Maize biochars accelerate short-term soil nitrogen dynamics in a loamy sand soil. Soil Biol Biochem 55:20-27. https://doi.org/10.1016/j. soilbio.2012.05.019

Nelson D, Sommers L (1982) Total carbon, organic carbon, and organic matter, methods of soil analysis, Part 2. Chemical and Microbiological Properties. p 539-580

Pan F, Chapman SJ, Li Y, Yao H (2017) Straw amendment to paddy soil stimulates denitrification but biochar amendment promotes anaerobic ammonia oxidation. J Soils Sediments. https://doi.org/10.1007/ s11368-017-1694-4

Persson T, Wirén A (1995) Nitrogen mineralization and potential nitrification at different depths in acid forest soils. Plant Soil 168(1):55-65

Prommer J, Wanek W, Hofhansl F, Trojan D, Offre P, Urich T, Schleper C, Sassmann S, Kitzler B, Soja G, Hood-Nowotny RC (2014) Biochar decelerates soil organic nitrogen cycling but stimulates soil nitrification in a temperate arable field trial. PLoS ONE 9(1):e86388. https://doi.org/10.1371/ journal.pone.0086388.g001

Rondon MA, Lehmann J, Ramírez J, Hurtado M (2007) Biological nitrogen fixation by common beans (Phaseolus vulgaris L.) increases with bio-char additions. Biol Fertil Soils 43(6):699-708
Schauss K, Focks A, Leininger S, Kotzerke A, Heuer H, Thiele-Bruhn S, Sharma S, Wilke BM, Matthies M, Smalla K, Munch JC, Amelung W, Kaupenjohann M, Schloter M, Schleper C (2009) Dynamics and functional relevance of ammonia-oxidizing archaea in two agricultural soils. Environ Microbiol $11(2): 446-456$. https://doi.org/10.1111/j.1462-2920.2008.01783.x

Schulz H, Glaser B (2012) Effects of biochar compared to organic and inorganic fertilizers on soil quality and plant growth in a greenhouse experiment. J Plant Nutr Soil Sci 175(3):410-422. https://doi.org/10.1002/ jpln.201100143

Shen JP, Zhang LM, Zhu YG, Zhang JB, He JZ (2008) Abundance and composition of ammonia-oxidizing bacteria and ammonia-oxidizing archaea communities of an alkaline sandy loam. Environ Microbiol 10(6):16011611. https://doi.org/10.1111/j.1462-2920.2008.01578.x

Shen W, Lin X, Shi W, Min J, Gao N, Zhang H, Yin R, He X (2010) Higher rates of nitrogen fertilization decrease soil enzyme activities, microbial functional diversity and nitrification capacity in a Chinese polytunnel greenhouse vegetable land. Plant Soil 337(1-2):137-150. https://doi.org/10.1007/ s11104-010-0511-2

Shen W, Lin X, Gao N, Shi W, Min J, He X (2011) Nitrogen fertilization changes abundance and community composition of ammonia-oxidizing bacteria. Soil Sci Soc Am J 75(6):2198-2205

Singh BP, Hatton BJ, Singh B, Cowie AL, Kathuria A (2010) Influence of biochars on nitrous oxide emission and nitrogen leaching from two contrasting soils. J Environ Qual 39(4):1224-1235

Song Y, Zhang X, Ma B, Chang SX, Gong J (2013) Biochar addition affected the dynamics of ammonia oxidizers and nitrification in microcosms of a coastal alkaline soil. Biol Fertil Soils 50(2):321-332. https://doi. org/10.1007/s00374-013-0857-8

Spokas KA, Reicosky DC (2009) Impacts of sixteen different biochars on soil greenhouse gas production. Ann Environ Sci 3:179-193

Steinbeiss S, Gleixner G, Antonietti M (2009) Effect of biochar amendment on soil carbon balance and soil microbial activity. Soil Biol Biochem 41(6):1301-1310. https://doi.org/10.1016/j.soilbio.2009.03.016

Tamura K, Stecher G, Peterson D, Filipski A, Kumar S (2013) MEGA6: molecular evolutionary genetics analysis version 6.0. Mol Biol Evol 30(12):27252729. https://doi.org/10.1093/molbev/mst197

Van Zwieten L, Kimber S, Downie A, Morris S, Petty S, Rust J, Chan KY (2010) A glasshouse study on the interaction of low mineral ash biochar with nitrogen in a sandy soil. Soil Res 48(7):569-576

Xia W, Zhang C, Zeng X, Feng Y, Weng J, Lin X, Zhu J, Xiong Z, Xu J, Cai Z, Jia Z (2011) Autotrophic growth of nitrifying community in an agricultural soil. ISME J 5(7):1226-1236. https://doi.org/10.1038/ismej.2011.5

Xu HJ, Wang XH, Li H, Yao HY, Su JQ, Zhu YG (2014) Biochar impacts soil microbial community composition and nitrogen cycling in an acidic soil planted with rape. Environ Sci Technol 48(16):9391-9399. https://doi. org/10.1021/es5021058

Zhao X, Wang S, Xing G (2013) Nitrification, acidification, and nitrogen leaching from subtropical cropland soils as affected by rice straw-based biochar: laboratory incubation and column leaching studies. J Soils Sediments 14(3):471-482. https://doi.org/10.1007/s11368-013-0803-2

Zheng H, Wang Z, Deng X, Herbert S, Xing B (2013) Impacts of adding biochar on nitrogen retention and bioavailability in agricultural soil. Geoderma 206:32-39. https://doi.org/10.1016/j.geoderma.2013.04.018 